\title{
Neonatal acute ethanol intoxication during the epidemic of COVID-19: a case report
}

\author{
Chao Sun ${ }^{1 \dagger}$, Yanyan Nie ${ }^{1 \dagger}$, Xiaoyu Cui ${ }^{1,2 \dagger}$, Fang Zhang ${ }^{1}$ and Yang Liu ${ }^{1 *}$ (])
}

\begin{abstract}
Background: After the outbreak of COVID-19, many families equip with 75\% ethanol to inactivate the SARS-CoV-2, which increases the risk of exposure to ethanol.

Case presentation: We reported a 25-day-old newborn who was diagnosed with neonatal acute ethanol intoxication with a presenting complaint of accidental consumption about $15 \mathrm{ml}$ formula milk containing $75 \%$ ethanol. His main clinical manifestations were irritability, flushed skin, tachycardia, tachypnea, and toxicology analysis detected ethanol. After timely gastric lavage and intravenous fluid replacement, he was cured and discharged.
\end{abstract}

Conclusions: During the COVID-19 epidemic, high concentration ethanol used for inactivating SARS-COV-2 should be placed reasonably and neonatal feeding safety should be emphasized. Timely diagnosis and symptomatic treatment are essential for the prevention and management of acute ethanol intoxication in newborns.

Keywords: COVID-19, Newborn, Acute ethanol intoxication

\section{Background}

The major epidemic of COVID-19 has emerged as a serious global public health threat, especially after the emergence of the more infectious Delta strain [1-3]. SARS-COV-2 can be effectively inactivated by $75 \%$ ethanol, according to Chinese expert's consensus [4]. As a result, many homes and public places have been equipped with $75 \%$ ethanol for surface disinfection of objects in order to inactivate the SARS-CoV-2, which increases the risk of exposure to ethanol. In 2021 alone, as of September 30, American Association of Poison Control Centers [5] had managed 18,168 ethanol exposure cases about hand sanitizer in children 12 years and younger. However, reports of high concentration of ethanol consumption in children are rare, especially in newborns. Therefore, we reported a case of acute ethanol

\footnotetext{
*Correspondence: tjetyyly@163.com

${ }^{\dagger}$ Chao Sun, Yanyan Nie and Xiaoyu Cui contributed equally to this work.

${ }^{1}$ Department of Neonatology, Tianjin Children's Hospital/Tianjin

University Children's Hospital, Tianjin 300134, P.R. China

Full list of author information is available at the end of the article
}

intoxication in a 25-day-old newborn boy to raise awareness of the disease.

\section{Case presentation}

A 25-day-old male newborn was admitted to Tianjin children's hospital two hours after accidental consumption of about $15 \mathrm{ml}$ formula milk containing $75 \%$ ethanol. According to his mother, two hours before admission, the boy ingested about $15 \mathrm{ml}$ formula milk, which was mistakenly mixed with $75 \%$ ethanol instead of water. $\mathrm{He}$ immediately developed flushing around his eyes, which gradually spread to his face and the whole body, accompanied by crying and irritability. We reported the incident to the Child Guidance Centre, who conducted a thorough investigation and careful questioning, and ultimately determined that the incident was an unintentional injury.

The boy was delivered by cesarean section at 40 weeks, with the birth weight of $3550 \mathrm{~g}$. His birth history was normal. When he was admitted to the hospital, he was irritated, responsive, cried loudly, and could smell a faint but definite odor of ethanol presenting on the breath. 
His face and body were flushed. A physical examination showed his body temperature was $37.1^{\circ} \mathrm{C}$, a respiratory rate was $50 \mathrm{breaths} / \mathrm{min}$, heart rate was $185 \mathrm{beats} / \mathrm{min}$, blood pressure was $83 / 40 \mathrm{mmHg}$, and $\mathrm{TcSO}_{2}$ was $98 \%$. Besides, his anterior fontanelle was flat and soft, and the examinations of lungs, cardiac, abdominal, nervous system, musculoskeletal, and extremity were normal. His toxicology analysis showed that $4.65 \mathrm{~mol} / \mathrm{L}(21.4 \mathrm{mg} / \mathrm{dl})$ of ethanol was detected in the blood and ethanol was also detected in the gastric juice. The remainder of the examination was normal.

The diagnosis of neonatal acute ethanol intoxication in this child was clear, according to a consensus on the management of acute ethanol intoxication [6]. As a result, we immediately gave normal saline gastric lavage until clear fluid was extracted, intravenous infusion of naloxone, as well as intravenous fluid replacement to maintain internal environment stability, and diuretic and defecation to promote excretion. After $7 \mathrm{~h}$ of hospitalization, his facial and body skin flushing completely subsided. $12 \mathrm{~h}$ after hospitalization, his mental response returned as usual and he was restarted on formula with good feeding tolerance. After 1 day in hospital, toxicological tests were performed again, and no ethanol was detected in the blood or gastric juices. On the third day of hospitalization, the child was cured and discharged. Periodical follow-up after discharge confirmed that the patient has reached the appropriate age for growth and psychomotor development.

\section{Discussion and conclusions}

Ethanol intoxication is uncommon in children, especially neonates [7]. According to previous reports, the clinical symptoms of acute ethanol intoxication are non-specific, and can be confused with other diseases, such as encephalitis, hydrocephalus, and anaphylactic shock [7, 8].Therefore, we reported a case of acute ethanol intoxication in a 25-day-old newborn boy to raise awareness of the disease.

In this report, we reported an acute ethanol intoxication incident in a 25-day-old newborn who was accidental consumption about $15 \mathrm{ml}$ formula milk containing $75 \%$ ethanol during the COVID-19. Unintentional mixing of alcohol in formula is another way for neonates to consume ethanol. In Japan, a case [8] was reported where sake (Japanese wine prepared from fermented rice) was mixed in a 15-day-old newborn girl's formula. The clinical features of the girl were flushed skin, tachycardia and low blood pressure indicating circulatory failure, somnolence and metabolic acidosis.

The main manifestations of the case we reported were irritability, flushing of facial and trunk skin, fast heart rate, breathing fast. These phenomena may involve multiple mechanisms, such as opioid peptides, prostaglandins, histamine, kinin, and catecholamines, which are related to acetaldehyde-activated vasodilation [9].

Although the symptoms of the boy we reported were mild, there are also apparent life-threatening acute ethanol intoxication events. For example, Chang-Teng $\mathrm{Wu}$ [10] reported an acute fatal alcohol intoxication incident due to child abuse in a 3-day-old newborn who was fed about $50 \mathrm{ml}$ of rice wine instead of milk by his father. When his father woke up the next day, he found that the neonate had general cyanosis and was not spontaneously breathing. Laboratory tests showed that the child had severe acidosis, abnormal renal and liver function. Unfortunately, after cardiopulmonarycerebral resuscitation, intermittent mandatory ventilation support and symptomatic treatment, the patient died.

An important reason for the treatment failure of this 3-day-old newborn is that he was not found in time. Consequently, the timely discovery of ethanol intoxication in a neonate is very important for ensuring his health and safety. Fortunately, the neonate in our case was taken to hospital shortly after being found to have accidentally consumed ethanol.

Because the child we reported had a history of ethanol consumption, we immediately gave normal saline gastric lavage until clear fluid was extracted, and diuretic and defecation, in order to promote ethanol excretion, as well as intravenous infusion of naloxone. Naloxone is considered to be an " amethystic agent " [11], which can antagonize acute ethanol intoxication through pharmacokinetic mechanism. One possible mechanism of naloxone antagonizing acute ethanol intoxication and its behavioral effects is to accelerate ethanol metabolism by reversing the redox state disorder of liver nicotinamide adenine dinucleotide (phosphate) couples caused by drugs [12]. Moreover, clinical studies $[13,14]$ in China have concluded that naloxone has a definite curative effect on acute ethanol intoxication with few side effects, which is a recommended method for treating ethanol intoxication at present. Therefore, we chose to treat the child with intravenous naloxone. And after the above treatments, the symptoms of the child were quickly alleviated.

To sum up, in the grim situation of the global COVID19 pandemic, the feeding safety of newborns should be taken seriously. The combination of medical history, physical examination, and ethanol poison detection is essential for the timely diagnosis and management of neonatal acute ethanol intoxication. In addition, high concentration ethanol used for inactivating SARSCOV-2 should also be placed reasonably and prominently marked during the COVID-19 epidemic. 


\section{Acknowledgements}

The authors would like to thank this neonate and his family for encouraging the authors to submit this case for publication and providing great help.

\section{Authors' contributions}

CS, YYN and FZ were in charge of the management of the patient during his hospitalization. XYC collected data, carried out literature search and wrote the first draft of the manuscript. CS, YYN and XYC revised the initial draft and finished the final manuscript. YL supervised the writing of the first draft and critically edited and revised the first draft, and he approved the final version after all corrections were made. All authors have read and approved the manuscript.

\section{Funding}

None.

\section{Availability of data and materials}

The datasets used and/or analyzed during the current case reports are available from the corresponding author on reasonable request.

\section{Declarations}

Ethics approval and consent to participate

Not applicable.

\section{Consent for publication}

The parents gave their written consent for their child's clinical details to be published in this study.

\section{Competing interests}

The authors declare that they have no competing interests.

\section{Author details}

'Department of Neonatology, Tianjin Children's Hospital/Tianjin University Children's Hospital, Tianjin 300134, P.R. China. ${ }^{2}$ Graduate College, Tianjin Medical University, Tianjin 300070, P.R. China.

\section{Received: 30 August 2021 Accepted: 15 January 2022}

Published online: 20 January 2022

\section{References}

1. Planas D, Veyer D, Baidaliuk A, Staropoli I, Guivel-Benhassine F, Rajah MM, Planchais C, Porrot F, Robillard N, Puech J, et al. Reduced sensitivity of SARS-CoV-2 variant Delta to antibody neutralization. Nature. 2021;596(7871):276-80

2. The species Severe acute respiratory syndrome-related coronavirus. classifying 2019-nCoV and naming it SARS-CoV-2. Nat Microbiol. 2020;5(4):536-44

3. Singh D, Joshi K, Samuel A, Patra J, Mahindroo N. Alcohol-based hand sanitisers as first line of defence against SARS-CoV-2: a review of biology, chemistry and formulations. Epidemiol Infect. 2020;148:e229.

4. Handbook of Prevention and Treatment of the Pneumonia Caused by the Novel Coronavirus (2019-nCoV). Accessed 18 October 2021 http://en.nhc. gov.cn/2020-02/06/c_76295.htm

5. American association of poison control centers-hand sanitizer. Accessed 18 October 2021 https://aapcc.org/track/hand-sanitizer

6. Consensus on the Diagnosis and Treatment of Acute Alcohol Intoxication. Chinese J Emerg Med. 2014;23(02):135-8. https://kns.cnki.net/kcms/ detail/detail.aspx?dbcode $=$ CJFD\&dbname $=$ CJFDZHYX\&filename $=J J Y Z 2$ 01402005\&uniplatform =NZKPT\&v=LLSOVBoaM5zamPbo5yPbvwieh RvLCrNUzlrMoUOXFKtgKdgb1OriSJH6wlwr_2zk.

7. Fong HF, Muller AA. An unexpected clinical course in a 29-day-old infant with ethanol exposure. Pediatr Emerg Care. 2014;30(2):111-3

8. Zaitsu M, Inada Y, Tashiro K, Hayashi C, Doi H, Hamasaki Y, Matsuo M. Acute alcohol intoxication in a 15-day-old neonate. Pediatr Int. 2013:55(6):792-4

9. Eriksson CJ. The role of acetaldehyde in the actions of alcohol (update 2000). Alcohol Clin Exp Res. 2001:25(5 Suppl ISBRA):15S-32S.
10. Wu CT, Hsia SH, Chen CL, Lee HY. Acute Fatal Alcohol Intoxication in a 3-Day-Old Neonate. Pediatr Neonatol. 2017;58(3):278-80.

11. Alkana RL, Noble EP. Amethystic agents-reversal of acute ethanol intoxication in humans. In Biochemistry and Pharmacology of Ethanol. 1979:2:349-74

12. Badawy AA, Evans M. The mechanism of the antagonism by naloxone of acute alcohol intoxication. Br J Pharmacol. 1981;74(3):514-6.

13. Zhou Y, Shi Y, Jiang Z. Effect of Naloxone on Acute Severe Alcoholism. Hebei Medical Journal. 2017:39(13):2024-6.

14. Zhao X, Gao X, Li D. Therapeutic effect and clinical safety of naloxone on acute alcoholism. Contemporary Medicine. 2020;26(34):63-5.

\section{Publisher's Note}

Springer Nature remains neutral with regard to jurisdictional claims in published maps and institutional affiliations.

Ready to submit your research? Choose BMC and benefit from:

- fast, convenient online submission

- thorough peer review by experienced researchers in your field

- rapid publication on acceptance

- support for research data, including large and complex data types

- gold Open Access which fosters wider collaboration and increased citations

- maximum visibility for your research: over 100M website views per year

At $B M C$, research is always in progress.

Learn more biomedcentral.com/submissions 